\title{
White Matter Hyperintensity Accumulation During Treatment of Late-Life Depression
}

\author{
Alexander Khalaf', Kathryn Edelman', Dana Tudorascu', Carmen Andreescu', Charles F Reynolds' and \\ Howard Aizenstein ${ }^{*, 1}$
}

'Western Psychiatric Institute and Clinic, Department of Psychiatry, University of Pittsburgh, Pittsburgh, PA, USA

\begin{abstract}
White matter hyperintensities (WMHs) have been shown to be associated with the development of late-life depression (LLD) and eventual treatment outcomes. This study sought to investigate longitudinal WMH changes in patients with LLD during a I2-week antidepressant treatment course. Forty-seven depressed elderly patients were included in this analysis. All depressed subjects started pharmacological treatment for depression shortly after a baseline magnetic resonance imaging (MRI) scan. At 12 weeks, patients underwent a follow-up MRI scan, and were categorized as either treatment remitters $(n=23)$ or non-remitters $(n=24)$. Among all patients, there was as a significant increase in $\mathrm{WMHs}$ over 12 weeks $(t(46)=2.36, P=0.02)$. When patients were stratified by remission status, non-remitters demonstrated a significant increase in WMHs $(t(23)=2.17, P=0.04)$, but this was not observed in remitters $(t(22)=1.09, P=0.29)$. Other markers of brain integrity were also investigated including whole brain gray matter volume, hippocampal volume, and fractional anisotropy. No significant differences were observed in any of these markers during treatment, including when patients were stratified based on remission status. These results add to existing literature showing the association between $\mathrm{WMH}$ accumulation and LLD treatment outcomes. Moreover, this is the first study to demonstrate similar findings over a short interval (ie 12 weeks), which corresponds to the typical length of an antidepressant trial. These findings serve to highlight the acute interplay of cerebrovascular ischemic disease and LLD.

Neuropsychopharmacology (2015) 40, 3027-3035; doi:I0.1038/npp.20I5.158; published online I July 2015
\end{abstract}

\section{INTRODUCTION}

Among community-dwelling older adults, late-life depression (LLD) has been estimated to affect $\sim 2 \%$ of patients based on strict diagnostic criteria (Beekman et al, 1999). Depression results in more years lived with a disability compared with any other disease, and also carries increased risks of suicide, medical comorbidities, and family caregiver burden (Casten et al, 1999; Garcia-Pena et al, 2013; Katon et al, 2010; Mulsant et al, 2006; Nelson et al, 2013). Unfortunately, LLD has a high treatment failure rate (ie 40-60\%) with current first-line agents (Lebowitz et al, 1997). Furthermore, patients who eventually respond to treatment will likely take longer to do so (ie 8-12 weeks) compared with patients with depression during other stages of life (Reynolds and Kupfer, 1999). For these reasons, much of LLD neuroimaging-based research has sought to identify markers that may help decrease the interval between diagnosis and remission. Specifically, multiple groups have sought to establish the presence of any structural or functional imaging markers that could inform clinicians of

\footnotetext{
*Correspondence: Dr H Aizenstein, Western Psychiatric Institute and Clinic, University of Pittsburgh, 38II O'Hara Street, Room 459, Pittsburgh, PA 15213, USA, Tel: + 412246 5464, Fax: + I 412586 9। I I, E-mail: aizen@pitt.edu

Received 16 January 2015; revised 26 May 2015; accepted 30 May 2015; accepted article preview online 10 June 2015
}

a patient's likelihood of achieving remission with a given antidepressant trial (Aizenstein et al, 2014).

Many magnetic resonance imaging (MRI) studies have shown that LLD is associated with demyelinating lesions, which are seen as white matter hyperintensities (WMHs) on MRI (Chen et al, 2006; Firbank et al, 2012; Herrmann et al, 2008; Krishnan et al, 2004; Taylor et al, 2005, 2013). In older adults, the etiology of these lesions is largely thought to be related to ischemic disease, but other neuropathologic processes may also have a role. This view has been supported by research demonstrating WMH's association with cardiovascular risk factors and pathological markers of ischemia such as arteriosclerosis, vascular ectasia, infarction, and upregulation of ischemic cellular processes (Chimowitz et al, 1989; Debette et al, 2011; Thomas et al, 2002; van Dijk et al, 2008). Furthermore, one of the most salient models of depression in older adults is the vascular depression hypothesis, which suggests that cerebrovascular ischemic damage promotes depressive symptoms (Alexopoulos et al, 1997; Butters et al, 2008). The relationship between WMHs and the vascular depression hypothesis is further strengthened by studies demonstrating that WMHs are associated with treatment outcomes (Aizenstein et al, 2011; Firbank et al, 2007; Heiden et al, 2005; Taylor et al, 2014). However, as several other studies have failed to find the association between WMHs and depression, the vascular depression hypothesis is not universally accepted (Aizenstein et al, 2011; 
Dotson et al, 2013). The failure to find robust cross-sectional associations between cerebrovascular disease and LLD does not prove that $\mathrm{WMH}$ changes do not promote depression, but may suggest that the association with depression is weak given the large variability of WMHs across elderly individuals. Another possibility is that the relationship between WMHs and depression is related more to the accumulation of white matter lesions rather than their overall burden. That is, individuals undergoing active ischemic white matter changes may be more likely to develop depression, or have more difficulty responding to treatment compared with those with static amounts of WMHs.

Few studies have characterized WMH changes over time, and of those that have, only differences over multiple years have been assessed (Chen et al, 2006; Firbank et al, 2012; Rosano et al, 2005; Schmidt et al, 1999). It is possible that $\mathrm{WMH}$ changes in LLD patients are occurring over more acute intervals than has been previously studied, and furthermore, that these changes may impact patient treatment trajectories. Evidence for or against such an effect would help guide further refinement of the vascular depression hypothesis. For this reason, we sought to investigate these brain changes over 12 weeks, which is the standard treatment interval for patients with LLD. The principal hypothesis of this study was that significant differences in WMHs would be observed in LLD patients between treatment initiation and 12 weeks. Furthermore, we expected a divergence in our results based on remission status following treatment.

As LLD etiology is not likely solely attributable to a single factor, we also used this experimental design to assess other MRI markers of brain integrity, including fractional anisotropy of white matter, whole brain gray matter, and bilateral hippocampal volumes. Fractional anisotropy, a measure of microstructural integrity of the white matter, is intimately related to WMHs from an etiological perspective, and previous research has been able to demonstrate similar associations with treatment outcomes in LLD (Alexopoulos et al, 2002, 2008, 2010). Whole brain gray matter and bilateral hippocampal volumes are more representative of the interplay of atrophy and possible neurotoxicity in LLD (Andreescu et al, 2008). However, there is some evidence to suggest that WMHs can effect cerebral volumes in some limited neural structures (Hannestad et al, 2006; Taylor et al, 2007). For these reasons, as a secondary hypothesis we expected to find significant differences among these markers in LLD patients over the 12 weeks of antidepressant treatment. Again, it was anticipated that stratification by remission status would yield differential results.

\section{MATERIALS AND METHODS}

\section{Study Design}

Approval for this study was granted by the University of Pittsburgh Institutional Review Board. The study duration was 12 weeks, during which participants underwent an antidepressant treatment trial. MRIs were performed before starting medication ('baseline scan') and 3 months later ('follow-up scan'). Study participants were drawn from multiple open-label treatment studies of LLD at the University of Pittsburgh's Advanced Center for Interventions and Services Research for the Study of Late Life Mood Disorders. Comprehensive protocols for these studies are detailed elsewhere (Saghafi et al, 2007; University of Pittsburgh, National Institutes of Health, 2008, 2009, 2010). Briefly, patients were $\geqslant 60$ years old, and identified as suffering from major depression using the Structured Clinical Interview for DSM-IV disorders. A baseline depression severity of at least moderate intensity was ensured by requiring patients to have a score of $\geqslant 15$ on either the Hamilton Rating Scale for Depression (HRSD) or Montgomery-Asberg Depression Rating Scale (MADRS), depending on the parent study. To exclude patients with cognitive impairments, patients were administered a MiniMental State Exam (MMSE) and required to have a score $>18$. Patients were excluded if they had a clinical history of any bipolar disorder, psychotic disorder, or alcohol/drug abuse within the past 3 months. Finally, patients with contraindications to MRI were excluded. This included the presence of any retained paramagnetic material, weight $>250 \mathrm{lbs}$, or claustrophobia. Patients were not excluded from this study based on prior antidepressant treatment nor was there a minimum antidepressant-free interval before enrolling.

As part of their respective treatment studies, patients received either escitalopram, duloxetine, or venlafaxine. Details regarding the administration and management of these medications were managed by the individual treatment studies. For patients receiving escitalopram, the starting dosage was $10 \mathrm{mg}$ per day, and was titrated up to $20 \mathrm{mg}$ per day based on clinical response. Patients receiving duloxetine began at $20 \mathrm{mg}$ per day, which could be increased to $120 \mathrm{mg}$ per day if necessary. Finally, patients receiving venlafaxine were titrated upwards from $37.5 \mathrm{mg}$ to a maximum dose of 150-300 mg based on standard guidelines from the manufacturer. After patients underwent their follow-up scan at 12 weeks, they were classified as remitters if their HRSD score was $\leqslant 7$ or their MADRS score was $\leqslant 10$. Selection of remission thresholds was based on two independent linear regression analyses, which both demonstrated that an HRSD score of $\leqslant 7$ corresponds to a MADRS score of $\leqslant 10$ (Heo et al, 2007; Zimmerman et al, 2004). The former threshold was originally proposed by Frank et al (1991), and has since become the dominant cutoff for remission in depression research (Kupfer, 2005).

\section{Image Acquisition and Analysis}

MRIs were performed at the MR Research Center at the University of Pittsburgh with a $3 \mathrm{~T}$ scanner (Siemens, Berlin, Germany). A T2-weighted fluid attenuation inversion recovery (FLAIR) sequence was used for WMH measurements in the axial orientation. Relevant sequence parameters included slice thickness $=3 \mathrm{~mm}$, number of slices $=48$, acquisition matrix $=212 \times 256 \mathrm{~mm}^{2}$, voxel size $=1 \times 1 \times 3$ $\mathrm{mm}^{3}$, repetition time $(\mathrm{TR})=9160 \mathrm{~ms}$, echo time $(\mathrm{TE})=90$ $\mathrm{ms}$, inversion time $(\mathrm{TI})=2500 \mathrm{~ms}$, and flip angle $=150^{\circ}$. WMHs were quantified with an automated method developed and validated by Wu et al (2006b). This method uses a fuzzy connectedness algorithm to automate WMH segmentation from T2-weighted FLAIR images. It then uses the John Hopkins University White Matter Atlas to automate the anatomic localization of WMHs using a demons-based 
image registration (Wakana et al, 2004). The localized WMH voxel counts were divided by total brain volume voxel counts to yield normalized WMH (nWMH) values. This step was performed to control for differences in total brain volume among patients, as this value may impact the rate of WMH development. Non-nWMH values were also calculated by multiplying the $\mathrm{WMH}$ voxel counts by voxel size.

For gray matter and hippocampal volume measurements, a T1-weighted high-resolution magnetization-prepared rapid gradient echo (MPRAGE) sequence in the axial orientation was used. Imaging parameters included slice thickness $=1$ $\mathrm{mm}$, number of slices $=176$, acquisition matrix $=224 \times 256$ $\mathrm{mm}^{2}$, voxel size $=1 \times 1 \times 1 \mathrm{~mm}^{3}, \mathrm{TR}=2300 \mathrm{~ms}, \mathrm{TE}=3430$ $\mathrm{ms}, \mathrm{TI}=900 \mathrm{~ms}$, and flip angle $=9^{\circ}$. Measures of whole brain gray matter and hippocampal volumes were extracted using Automated Labeling Pathway, a method we developed to implement Atlas-based segmentation of MR images. This is a semiautomated method that labels regions of interest on the high-resolution T1 image of each subject (Aizenstein et al, 2005; Rosano et al, 2005; Wu et al, 2006a). These values were both normalized by dividing by total intracranial volume. A diffusion tensor imaging sequence in the axial orientation was used to assess white matter microstructure. Images were acquired with the following parameters: slice thickness $=3$ $\mathrm{mm}$, number of slices $=40$, acquisition matrix $=256 \times 256$ $\mathrm{mm}^{2}$, voxel size $=2 \times 2 \times 3 \mathrm{~mm}^{3}, \mathrm{TR}=5300 \mathrm{~ms}, \mathrm{TE}=88 \mathrm{~ms}$, $\mathrm{TI}=250 \mathrm{~ms}$, and flip angle $=90^{\circ}$, diffusion directions $=12$, diffusion values $b=0 \mathrm{~s} / \mathrm{mm}^{2}$ and $b=1000 \mathrm{~s} / \mathrm{mm}^{2}$, four repeats, and radial generalized autocalibrating partially parallel acquisitions $($ GRAPPA $)=2$. Fractional anisotropy of 'normal-appearing' white matter was estimated with TractBased Spatial Statistics, part of the FSL software package (Analysis Group, Oxford, UK) (Jenkinson et al, 2012; Smith et al, 2006). WMHs were masked out of this analysis.

\section{Statistical Analysis}

After patients were categorized based on remission status, we performed statistical analysis of pertinent covariates comparing baseline characteristics between the groups. A twosample Student's $t$-test was used to assess for significant differences between remitters and non-remitters with respect to age, MMSE, baseline depression rating scores, Cumulative Illness Rating Scale-Geriatric (CIRSG) vascular score, and antidepressant end dosage. A $\chi^{2}$ test was performed to detect significant differences with respect to various dichotomized characteristics, including gender, depression onset (ie earlyor late-onset LLD), anti-inflammatory medication use, and benzodiazepine use.

The nWMH values among all patients were compared between baseline and follow-up using a paired $t$-test to determine if WMHs changed over the treatment period. Patients were then stratified by remission status, and again a paired $t$-test was used to compare nWMH means between baseline and follow-up in each group. To assess for any differences in nWMH group means at baseline, a two-sample $t$-test was performed. Identical analyses were performed for normalized gray matter volumes, normalized hippocampal volumes, and fractional anisotropy. All statistical tests were two-tailed and considered statistically significant at an $\alpha$ level $<0.05$. Statistical analysis was performed using SPSS statistical software (IBM, Endicott, NY).

\section{RESULTS}

Of the 47 depressed subjects included in this protocol, 23 met the criteria for remission, whereas 24 were still depressed at follow-up according to their depression rating scores. In the analysis of baseline characteristics between remitters and non-remitters, the only significant differences observed were with respect to escitalopram and venlafaxine antidepressant end dosages $(t=2.26$, d.f. $=15, P=0.04 ; t=2.76$, d.f. $=25$, $P=0.01$ ), and proportion of patients with early- $v s$ late-onset LLD $\left(\chi^{2}=5.25\right.$, d.f. $\left.=1, P=0.02\right)$. Table 1 fully summarizes this analysis.

In assessing our primary hypothesis, we sought to determine whether among all patients there was a significant difference in nWMHs (ie WMH voxels/total brain voxels) between baseline and follow-up at 12 weeks. A significant increase in nWMHs $(t=2.36$, d.f. $=46, P=0.02)$ among all patients was observed. When the patient sample was stratified by remission status, non-remitters demonstrated a significant increase in nWMHs between baseline and follow-up $(t=2.17$, d.f. $=23, \quad P=0.04)$, but this finding was not replicated in the remitters $(t=1.09$, d.f. $=22$, $P=0.29$ ). These findings persisted even when the analysis was repeated with non-nWMH values. Finally, the baseline nWMHs were not significantly different between remitters and non-remitters $(t=1.27$, d.f. $=28.13, P=0.10)$. These results are summarized in Table 2 and Figure 1.

An exploratory analysis was also performed to identify any potential confounders between remission status and nWMHs. The factors antidepressant type, early- $v s$ late-onset LLD (ie threshold of 60 years), current age, Cumulative Illness Rating Scale-Geriatric vascular score, anti-inflammatory medication use, and benzodiazepine use were selected as the most likely candidates to be associated with remission status and nWMHs. Patients were stratified based on each of these factors, and underwent paired $t$-tests comparing day 1 and week $12 \mathrm{nWMHs}$. This analysis revealed three of the above factors as differentially affecting accumulation of nWMHs. Stratification based on antidepressant type revealed that only escitalopram-treated patients significantly accumulated nWMHs $(t=2.42$, d.f. $=15, P=0.03)$. In the early/late-onset LLD stratification, the early-onset LLD patients demonstrated a significant increase in nWMH $(t=2.93$, d.f. $=31, P=0.02)$, whereas the late-onset LLD did not $(t=0.77$, d.f. $=14$, $P=0.45$ ). Finally, stratification based on anti-inflammatory medication use revealed an increase in nWMHs only among patients who did not use these agents $(t=2.62$, d.f. $=20$, $P=0.02)$. As an additional step, patients within each of these significant subsamples were further stratified based on remission status. Within the escitalopram and early-onset LLD samples, only non-remitters demonstrated significant increases in nWMHs $(t=2.45$, d.f. $=7, P=0.04 ; t=2.18$, d.f. $=19, P=0.04)$. A similar finding was observed in the sample of patients who did not use anti-inflammatory agents, but it was marginally nonsignificant $(t=2.12$, d.f. $=13$, $P=0.054)$. This exploratory analysis is comprehensively detailed in Table 3.

In addressing the study's secondary hypothesis, we analyzed the changes in whole brain gray matter volume, bilateral hippocampal volumes, and fractional anisotropy of normal-appearing white matter between baseline and follow-up. When each of these markers among all patients 
Table I Patient Characteristics

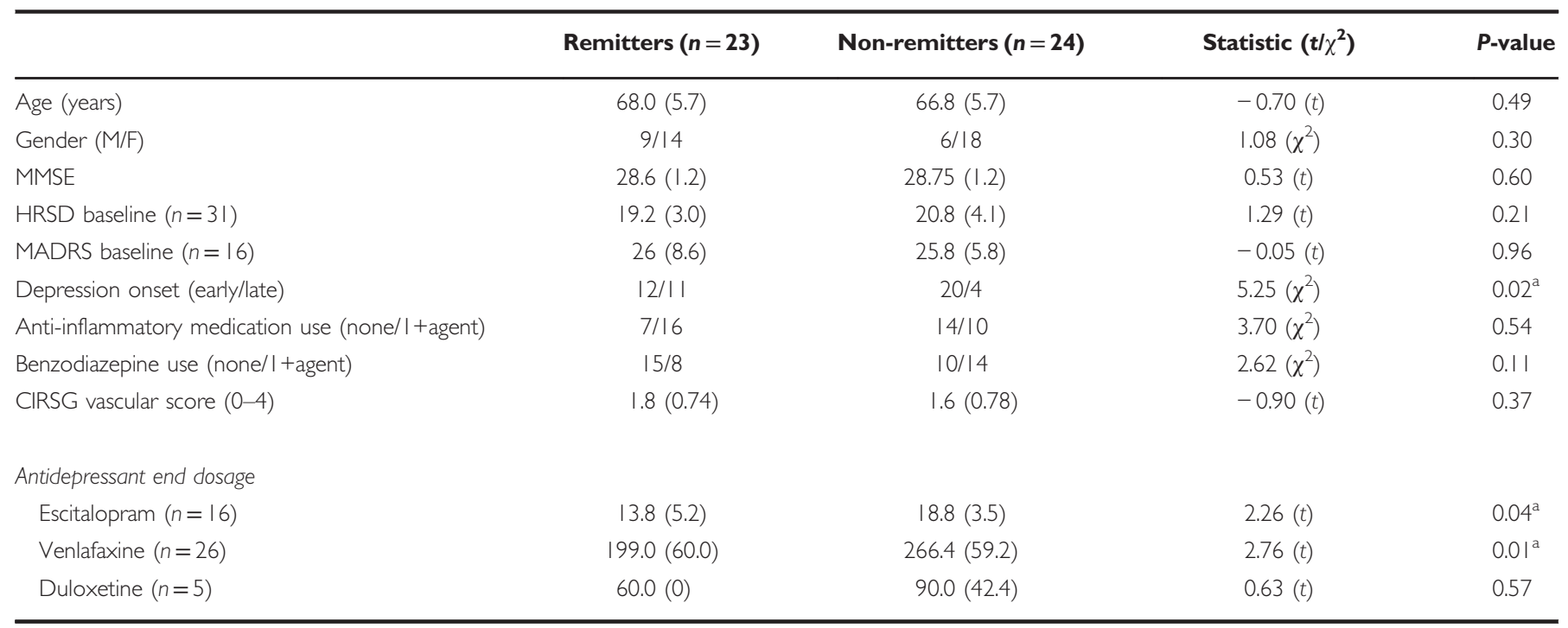

Abbreviations: CIRSG, Cumulative IIIness Rating Scale-Geriatric; HRSD, Hamilton Rating Scale for Depression; MADRS, Montgomery Asberg Depression Rating Scale; MMSE, Mini-Mental State Exam.

${ }^{a}$ Statistical significance. Data are represented as mean (SD), unless otherwise indicated.

Table 2 Change in White Matter Hyperintensities During Treatment

\begin{tabular}{|c|c|c|c|c|c|c|}
\hline \multicolumn{7}{|l|}{ Normalized WMHs (\%) } \\
\hline Overall $(n=47)$ & $1.38 \times 10^{-3}\left(1.89 \times 10^{-3}\right)$ & $1.71 \times 10^{-3}\left(2.36 \times 10^{-3}\right)$ & $3.27 \times 10^{-4}\left(4.76 \times 10^{-5}\right.$ to $\left.6.07 \times 10^{-4}\right)$ & 2.36 & 46 & $0.02^{\mathrm{a}}$ \\
\hline Remitters $(n=23)$ & $1.03 \times 10^{-3}\left(8.22 \times 10^{-4}\right)$ & $1.23 \times 10^{-3}\left(1.18 \times 10^{-3}\right)$ & $2.03 \times 10^{-4}\left(1.84 \times 10^{-4}\right.$ to $\left.5.90 \times 10^{-4}\right)$ & 1.09 & 22 & 0.29 \\
\hline Non-remitters $(n=24)$ & $1.72 \times 10^{-3}\left(2.49 \times 10^{-3}\right)$ & $2.17 \times 10^{-3}\left(3.06 \times 10^{-3}\right)$ & $4.47 \times 10^{-4}\left(2.04 \times 10^{-4}\right.$ to $\left.8.73 \times 10^{-4}\right)$ & 2.17 & 23 & $0.04^{\mathrm{a}}$ \\
\hline \multicolumn{7}{|l|}{ Non-normalized WMHs $\left(\mathrm{cm}^{3}\right)$} \\
\hline Overall $(n=47)$ & $0.56(0.77)$ & $0.68(0.94)$ & 0.12 (0.02 to 0.22$)$ & 2.45 & 46 & $0.02^{\mathrm{a}}$ \\
\hline Remitters $(n=23)$ & $0.41(0.30)$ & $0.49(0.45)$ & $0.08(-0.06$ to 0.22$)$ & 1.19 & 22 & 0.25 \\
\hline Non-remitters $(n=24)$ & $0.71(1.03)$ & $0.87(1.22)$ & $0.16(0.01$ to 0.31$)$ & 2.22 & 23 & $0.04^{\mathrm{a}}$ \\
\hline
\end{tabular}

Abbreviations: d.f., degrees of freedom; WMH, normalized white matter hyperintensities.

${ }^{\text {a}}$ Statistical significance $(P<0.05)$. Data are represented as mean $(\mathrm{SD})$, unless otherwise indicated.

were compared between these time points, no significant differences were observed. Upon stratification by remission status, no significant differences were observed either. However, the data did demonstrate an increase in bilateral hippocampal volumes between baseline and follow-up among remitters, but this increase did not reach statistical significance $(t=-1.93$, d.f. $=22, P=0.07)$. Finally, when comparing baseline gray matter volume, hippocampal volume, and fractional anisotropy between remitters and non-remitters, no significant differences were observed $(t=0.008$, d.f. $=45, P=0.99 ; t=-0.163$, d.f. $=45, P=0.87$; $t=-0.436$, d.f. $=45, P=0.67)$. Table 4 summarizes these results.

\section{DISCUSSION}

This data suggests there is an increase in WMHs among depressed subjects during the 12 -week treatment course, and that this effect is primarily driven by non-remitters. The primary implication of these findings is that an increase in WMHs over time may be associated with potentiation of depressive symptoms. The vascular depression hypothesis suggests that WMHs are a likely manifestation of subclinical cerebrovascular disease. This is supported by multiple studies linking WMHs with factors such as hypertension, tobacco use, and diabetes, which are all known contributors to both large and small vessel disease (Herrmann et al, 2008). It is thought that low-level cerebrovascular disease results in disruption of frontostriatal circuits, which are necessary for mood regulation (Alexopoulos et al, 1997; Lenze et al, 1999). Therefore, one possible interpretation of the association between WMH accumulation and non-remission is that the former represents further degradation of these neural pathways, which are critical to patient recovery. This hypothesis arises from a number of previous studies, which demonstrate that WMHs and microstructural abnormalities in specific frontostriatal circuit structures are associated with 


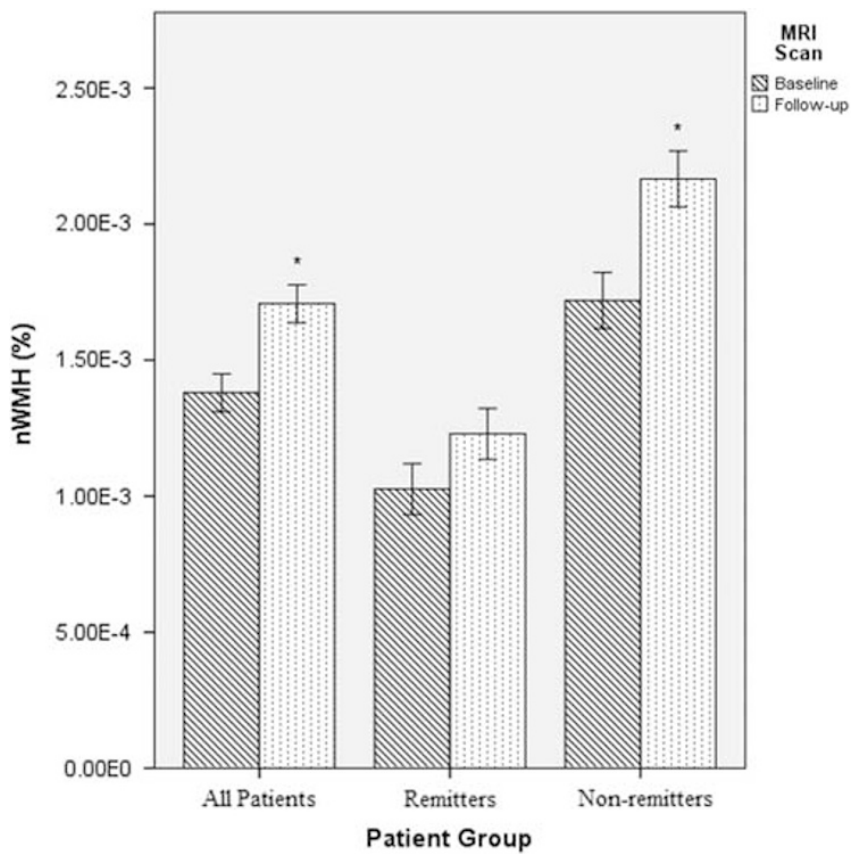

Figure I Change in normalized white matter hyperintensities ( $\mathrm{WWMH}$ ) during a 12-week antidepressant course. Patient results demonstrate significant nWMH increased among all patients and non-remitters. Data were corrected for between-subject variability to accurately visualize withinsubject statistical design. Data were presented as mean \pm SEM.

treatment outcomes in LLD (Alexopoulos et al, 2002, 2008, 2010; Taylor et al, 2014).

It is also a distinct possibility that this effect is bidirectional. That is, depression may promote the accumulation of WMHs, and perhaps these negative effects are mitigated when depression enters remission. The bidirectional nature of depression and white matter changes is described in recent reviews of vascular depression (Alexopoulos, 2005; Teper and O'Brien, 2008). Multiple explanations have been proposed for depression's effect on WMH development including depression-induced chronic hypothalamus-pituitary-adrenal (HPA) axis activation. Persistently elevated cortisol levels, as is seen in depression, is known to accelerate the formation of atherosclerotic plaques and promote vascular disease. Another suggested mechanism is the upregulation of inflammatory cytokines, which has been well documented in depressed patients. Evidence currently supports the role of these cytokines in mediating endothelial dysfunction, and they are also known to interact with the HPA axis, possibly amplifying this pathway (Teper et al, 2008). The existence of these and other plausible pathophysiological pathways indicates that the development of WMHs is likely multifactorial, and furthermore indicates that the bidirectional relationship between depression and WMHs is complex and currently incompletely characterized.

This study's exploratory analysis of possible confounders supports this understanding, as it reveals multiple factors beyond remission status, which affect accumulation of WMHs. These included antidepressant type, early- vs lateonset LLD, and anti-inflammatory use. Upon further substratification within these categories, it becomes clear that each of these factors association with WMHs is primarily driven by non-remitters. In the context of baseline comparisons of these factors between remitters and nonremitters, it appears that both escitalopram treatment and anti-inflammatory medication use themselves are not related to remission status, but instead may have divergent impacts upon WMHs among remitters and non-remitters (see Table 1). Specifically, escitalopram treatment and non-use of anti-inflammatory agents may result in accelerated $\mathrm{WMH}$ accumulation only among non-remitters. Although antiinflammatory use can readily be understood to influence inflammatory and thrombotic pathways resulting in altered WMH development, escitalopram's effect on WMHs has a more nuanced interpretation. Selective serotonin reuptake inhibitors (SSRIs) such as escitalopram have been identified as potent disruptors of normal hemostasis as compared with other antidepressant classes with impairment in platelet aggregation and prolonged bleeding time, effects that may possibly inhibit thromboembolic events (Halperin and Reber, 2007). Conversely, it has been proposed that SSRIs stimulate vasoconstriction via serotonin receptors on vascular smooth muscle (Wu et al, 2011). Regardless of these seemingly contradictory effects on perfusion, these agents have been extensively associated with both cardiovascular disease and cerebrovascular events (Chen et al, 2008; Smoller et al, 2009; Weeke et al, 2012; Whang et al, 2009; Wu et al, 2011). The two studies that specifically examined the effect of SSRIs on WMHs both found an increase in WMHs among SSRI-treated patients, but only one demonstrated a statistically significant relationship (Grool et al, 2013; Steffens et al, 2008). From this information, it can be surmised that there may indeed be an effect of SSRIs on WMH accumulation, but further study is required to fully elucidate this relationship and also explore how serotonin-norepinephrine reuptake inhibitors (eg venlafaxine and duloxetine) may affect WMHs, for which data are currently lacking.

In contrast to antidepressant-type and anti-inflammatory medication use, which are only associated with $\mathrm{WMH}$ accumulation, early-onset LLD appears to be associated with both remission status and WMH accumulation according to the comparison of remitters/non-remitter characteristics and the exploratory analysis. Therefore, depression onset can be concluded to be a likely confounder in this analysis, and may account for the previously demonstrated association of WMHs and treatment outcomes in other studies, which did not assess the effect of this factor (Chen et al, 2006; Taylor et al, 2003; Teodorczuk et al, 2007). The significantly increased number of non-remitters in the early-onset LLD group may at first seem counterintuitive, provided the prevailing view that late-onset LLD is the more difficult to treat form of the disease. However, studies examining this association have been mixed, casting doubt on the validity of this perspective (Alexopoulos et al, 1996; Dew et al, 1997; Kozel et al, 2008; Reynolds et al, 1998). Overall, the findings of the exploratory analysis suggest that the intricate relationship between WMHs and remission status cannot fully be separated from other casual factors. Instead, it is likely more accurate to conceptualize WMHs as a manifestation of multiple underlying competing interactions, which ultimately affect LLD treatment outcomes.

Although this study is unable to fully elucidate etiological considerations, its results are able to demonstrate that WMH accumulation may be as important as cumulative WMH burden in the development and treatment trajectories of 
Table 3 Exploratory Analysis

\begin{tabular}{|c|c|c|c|c|c|c|}
\hline & Baseline & Follow-up & Mean difference $(95 \% \mathrm{Cl})$ & $t$-Score & d.f. & $P$-value \\
\hline \multicolumn{7}{|l|}{ Antidepressant } \\
\hline Escitalopram $(n=16)$ & $1.65 \times 10^{-3}\left(2.61 \times 10^{-3}\right)$ & $2.18 \times 10^{-3}\left(2.84 \times 10^{-3}\right)$ & $5.31 \times 10^{-4}\left(6.27 \times 10^{-5}\right.$ to $\left.9.98 \times 10^{-4}\right)$ & 2.42 & 15 & $0.029 *$ \\
\hline Non-remitters $(n=8)$ & $2.29 \times 10^{-3}\left(3.56 \times 10^{-3}\right)$ & $3.00 \times 10^{-3}\left(3.60 \times 10^{-3}\right)$ & $7.14 \times 10^{-4}\left(2.60 \times 10^{-5}\right.$ to $\left.1.40 \times 10^{-3}\right)$ & 2.45 & 7 & $0.044 *$ \\
\hline Venlafaxine $(n=26)$ & $1.33 \times 10^{-3}\left(1.51 \times 10^{-3}\right)$ & $1.64 \times 10^{-3}\left(2.23 \times 10^{-3}\right)$ & $3.10 \times 10^{-4}\left(-1.09 \times 10^{-4}\right.$ to $\left.7.30 \times 10^{-4}\right)$ & 1.52 & 25 & 0.140 \\
\hline Duloxetine $(n=5)$ & $7.62 \times 10^{-4}\left(5.28 \times 10^{-4}\right)$ & $5.28 \times 10^{-4}\left(2.48 \times 10^{-4}\right)$ & $-2.34 \times 10^{-4}\left(-8.40 \times 10^{-4}\right.$ to $\left.3.73 \times 10^{-4}\right)$ & -1.07 & 4 & 0.345 \\
\hline \multicolumn{7}{|l|}{ Depression onset } \\
\hline Early onset $(n=32)$ & $1.10 \times 10^{-3}\left(1.53 \times 10^{-3}\right)$ & $1.48 \times 10^{-3}\left(2.21 \times 10^{-3}\right)$ & $3.80 \times 10^{-4}\left(5.50 \times 10^{-5}\right.$ to $\left.7.06 \times 10^{-4}\right)$ & 2.39 & 31 & $0.023 *$ \\
\hline Remitters $(n=12)$ & $8.36 \times 10^{-4}\left(5.01 \times 10^{-4}\right)$ & $1.06 \times 10^{-3}\left(6.68 \times 10^{-4}\right)$ & $2.20 \times 10^{-4}\left(-2.68 \times 10^{-4}\right.$ to $\left.7.07 \times 10^{-4}\right)$ & 0.99 & 11 & 0.343 \\
\hline Non-remitters $(n=20)$ & $1.26 \times 10^{-3}\left(1.90 \times 10^{-3}\right)$ & $1.73 \times 10^{-3}\left(2.74 \times 10^{-3}\right)$ & $4.77 \times 10^{-4}\left(1.79 \times 10^{-5}\right.$ to $\left.9.36 \times 10^{-4}\right)$ & 2.18 & 19 & $0.042 *$ \\
\hline Late onset $(n=15)$ & $1.98 \times 10^{-3}\left(2.44 \times 10^{-3}\right)$ & $2.19 \times 10^{-3}\left(2.67 \times 10^{-3}\right)$ & $2.15 \times 10^{-4}\left(-3.82 \times 10^{-4}\right.$ to $\left.8.11 \times 10^{-4}\right)$ & 0.77 & 14 & 0.453 \\
\hline \multicolumn{7}{|l|}{ CIRSG vascular } \\
\hline Score: $0-\mid(n=9)$ & $5.72 \times 10^{-4}\left(4.72 \times 10^{-4}\right)$ & $9.27 \times 10^{-4}\left(7.58 \times 10^{-4}\right)$ & $3.55 \times 10^{-4}\left(-5.75 \times 10^{-5}\right.$ to $\left.7.68 \times 10^{-4}\right)$ & 1.99 & 8 & 0.082 \\
\hline Score: $0-2(n=38)$ & $1.57 \times 10^{-3}\left(2.04 \times 10^{-3}\right)$ & $1.89 \times 10^{-3}\left(2.57 \times 10^{-3}\right)$ & $3.21 \times 10^{-4}\left(-1.86 \times 10^{-5}\right.$ to $\left.6.60 \times 10^{-4}\right)$ & 1.92 & 37 & 0.063 \\
\hline \multicolumn{7}{|l|}{ Anti-inflammatory use } \\
\hline None $(n=21)$ & $1.15 \times 10^{-3}\left(2.11 \times 10^{-3}\right)$ & $1.58 \times 10^{-3}\left(2.24 \times 10^{-3}\right)$ & $4.28 \times 10^{-4}\left(8.72 \times 10^{-5}\right.$ to $\left.7.70 \times 10^{-4}\right)$ & 2.62 & 20 & $0.016 *$ \\
\hline Remitters $(n=7)$ & $7.08 \times 10^{-4}\left(3.81 \times 10^{-4}\right)$ & $1.12 \times 10^{-3}\left(8.51 \times 10^{-4}\right)$ & $4.15 \times 10^{-4}\left(-2.97 \times 10^{-4}\right.$ to $\left.1.13 \times 10^{-3}\right)$ & 1.43 & 6 & 0.204 \\
\hline Non-remitters $(n=14)$ & $1.38 \times 10^{-3}\left(2.58 \times 10^{-3}\right)$ & $1.81 \times 10^{-3}\left(2.69 \times 10^{-3}\right)$ & $4.35 \times 10^{-4}\left(-8.74 \times 10^{-6}\right.$ to $\left.8.79 \times 10^{-4}\right)$ & 2.12 & 13 & 0.054 \\
\hline$>1$ Agent $(n=26)$ & $1.56 \times 10^{-3}\left(1.70 \times 10^{-3}\right)$ & $1.81 \times 10^{-3}\left(2.49 \times 10^{-3}\right)$ & $2.46 \times 10^{-4}\left(-1.98 \times 10^{-4}\right.$ to $\left.6.89 \times 10^{-4}\right)$ & 1.14 & 25 & 0.264 \\
\hline \multicolumn{7}{|l|}{ Benzodiazepine use } \\
\hline
\end{tabular}

Abbreviations: CIRSG, Cumulative Illness Rating Scale-Geriatric; d.f., degrees of freedom.

Data are represented as mean (SD), unless otherwise indicated.

Table 4 Change in Gray Matter Volume, Hippocampal Volume, and Fractional Anisotropy

\begin{tabular}{lcccccc}
\hline & Baseline & Follow-up & Mean difference (95\% Cl) & t-Score & d.f. & P-value \\
\hline Remitters (n=23) & & & & & \\
nGMV (\%) & $3.20 \times 10^{-1}\left(2.15 \times 10^{-2}\right)$ & $3.20 \times 10^{-1}\left(2.00 \times 10^{-2}\right)$ & $1.06 \times 10^{-4}\left(-4.16 \times 10^{-3}\right.$ to $\left.4.37 \times 10^{-3}\right)$ & -0.05 & 22 & 0.96 \\
nHCV (\%) & $5.86 \times 10^{-3}\left(5.07 \times 10^{-4}\right)$ & $5.98 \times 10^{-3}\left(4.32 \times 10^{-4}\right)$ & $1.20 \times 10^{-4}\left(-9.07 \times 10^{-6}\right.$ to $\left.2.49 \times 10^{-4}\right)$ & -1.93 & 22 & 0.07 \\
FA & $3.74 \times 10^{-1}\left(1.22 \times 10^{-2}\right)$ & $3.73 \times 10^{-1}\left(1.44 \times 10^{-2}\right)$ & $-9.11 \times 10^{-4}\left(-3.86 \times 10^{-3}\right.$ to $\left.2.04 \times 10^{-3}\right)$ & 0.64 & 22 & 0.53 \\
& & & & & & \\
Non-remitters (n=24) & & & & & \\
nGMV (\%) & $3.20 \times 10^{-1}\left(2.04 \times 10^{-2}\right)$ & $3.17 \times 10^{-1}\left(2.19 \times 10^{-2}\right)$ & $-3.39 \times 10^{-3}\left(-8.38 \times 10^{-3}\right.$ to $\left.1.61 \times 10^{-3}\right)$ & 1.40 & 23 & 0.17 \\
nHCV (\%) & $5.83 \times 10^{-3}\left(6.29 \times 10^{-4}\right)$ & $5.72 \times 10^{-3}\left(5.68 \times 10^{-4}\right)$ & $-1.08 \times 10^{-4}\left(-2.59 \times 10^{-4}\right.$ to $\left.4.18 \times 10^{-5}\right)$ & 1.49 & 23 & 0.15 \\
FA & $3.72 \times 10^{-1}\left(1.34 \times 10^{-2}\right)$ & $3.72 \times 10^{-1}\left(1.18 \times 10^{-2}\right)$ & $-8.86 \times 10^{-4}\left(-4.54 \times 10^{-3}\right.$ to $\left.2.76 \times 10^{-3}\right)$ & 0.50 & 23 & 0.62 \\
\hline
\end{tabular}

Abbreviations: d.f., degrees of freedom; FA, fractional anisotropy; nGMV, normalized gray matter volume; nHCV, normalized bilateral hippocampus volume.

Data are represented as mean (SD), unless otherwise indicated.

LLD. The vascular depression hypothesis has been supported by numerous studies showing that development of late-onset LLD is associated with greater severity of WMHs. Furthermore, research has demonstrated that baseline WMHs are associated with treatment outcomes in these patients
(Heiden et al, 2005; O'Brien et al, 1998). Our results were able to demonstrate that non-remitters had higher baseline WMHs compared with responders, but this difference was nonsignificant. The more robust association was found between accumulation of WMHs over 12 weeks and failure 
to enter remission during this interval. These findings are corroborated by the work of Taylor et al (2003) who were the first group to demonstrate the importance of $\mathrm{WMH}$ accumulation in the treatment of LLD. They followed a cohort of 133 depressed elderly patients over 2 years, and observed significantly more WMH accumulation in those patients who were unable to achieve sustained remission with standard pharmacotherapy. Other groups have been able to replicate these findings over similarly long time spans (Chen et al, 2006; Teodorczuk et al, 2007). The novelty of the current study is its demonstration of comparable findings over the much shorter interval of 12 weeks. Extrapolating this study's mean change in non-nWMHs out to 2 years $\left(0.96 \mathrm{~cm}^{3}\right)$ yields results of comparable magnitude to calculated 2-year differences from Taylor et al. (2003) (1.53 $\left.\mathrm{cm}^{3}\right)$ and Chen et al. (2006) $\left(1.67 \mathrm{~cm}^{3}\right)$. The discrepancy in these values may suggest an acceleration of $\mathrm{WMH}$ accumulation overtime among LLD patients, but given the differences in study design this interpretation is merely speculative.

In this study's secondary analysis, a marginally nonsignificant increase in bilateral hippocampal volumes $(P=0.07)$ was demonstrated in treatment responders. Reduction in hippocampal volumes in patients with depression has been extensively documented in the literature (Campbell et al, 2004; Videbech and Ravnkilde, 2004). The duration of depression has also been shown to be inversely correlated with hippocampal volume, which has prompted many to hypothesize that depression mediates hippocampus neurotoxicity (MacQueen et al, 2003; Sheline et al, 1996). Research into antidepressant therapy's effect on hippocampal volume is still very limited. Animal models have been able to demonstrate that chronic antidepressant administration, including SSRI and SNRI agents, mediates neurogenesis and increased hippocampal volumes (Hajszan et al, 2005; Malberg et al, 2000). In patients with posttraumatic stress disorder, Vermetten et al (2003) demonstrated that paroxetine administration over a treatment period of 9-12 months was associated with an increase in mean hippocampal volume and reduction of symptoms. However, the evidence for a similar effect in depression is currently non-existent, with the only published study by Vythilingam et al (2004) not finding any difference in hippocampal volume in 22 depressed patients over 7 months of treatment with an SSRI. The results of the present study may suggest that antidepressant-stimulated hippocampal neurogenesis is indeed occurring during treatment of depression, but that the effect is differentially distributed based on treatment response. Measureable differences in hippocampal volume may also take considerably longer than 12 weeks to develop despite the presence of neurogenesis. Unfortunately, the nonsignificant nature of this finding and the study's methodological limitations preclude any real conclusions from being drawn. Rather, this finding simply stands to highlight this as an area that may yield more substantive results with further research.

This study's primary limitation was its inclusion of patients from multiple clinical trials. This resulted in patients undergoing distinct treatment protocols and being assessed with different sets of depression rating scales (HRSD, MADRS). Although care was taken to select similar remission thresholds between these two scales, it is possible that variations in these instruments resulted in non-uniform remission classifications that impacted the results. The absence of a control group in this analysis is also an important limitation to recognize as it makes it difficult to assess the presence of any systematic measurement bias. Additionally, individual patient physiological factors, which were not assessed, may have influenced this study's findings. Most notably, patient hydration status has been shown to affect brain volumes, but the specific effect on hippocampal volumes and $\mathrm{WMH}$ burden has not yet been demonstrated and requires further study (Streitburger et al, 2012). It is important to note that this study did not have exclusion criteria based on prior antidepressant treatment nor require a minimum antidepressant free interval before beginning the study. Therefore, previous antidepressant treatment, especially proximal to the study, may have impacted the various markers we investigated. Finally, it is essential to realize that accumulation of WMHs is likely related to multiple factors, and this investigation's limited sample size prevent it from being able to fully explicate these details.

This study contributes to growing evidence that WMHs are associated with LLD. Our findings expand upon existing knowledge by demonstrating that WMH accumulation occurs over significantly shorter intervals (ie 12 weeks) than has been previously shown. Additionally, these changes are differentially distributed among those patients who are eventually classified as non-remitters, which indicates that the relationship between WMH accumulation and LLD is consequential even during short antidepressant treatment courses.

\section{FUNDING AND DISCLOSURE}

The following funding sources contributed to this study as a whole, including design and conduct, collection, management, analysis, and interpretation of the data, as well as preparation and review of this manuscript. Grant support included: NIH Grants T32-MH19986, R25-MH060473, R01 MH37869, K02-MH064190, K23-MH086686, K23-MH64678, K01-MH01684, P30 MH52247, and P50 AG05133-18S2, University of Pittsburgh Clinical Scientist Training Program (CSTP) and Clinical and Translational Science Institute (UL1 TL1TR000005), NIMH Medical Student Research Fellowship administered by University of Pittsburgh (R25 MH05431818). Dr Reynolds has received support from Bristol Meyers Squibb, Forrest Labs, Lily, and Pfizer in the form of pharmaceutical supplies used in the conduct of clinical trials used comprising this research. The remaining authors declare no conflict of interest.

\section{ACKNOWLEDGMENTS}

We thank Sarah Walker, Jeff Krystek, and Erica Tamburo who were instrumental in conducting this research.

\section{REFERENCES}

Aizenstein HJ, Andreescu C, Edelman KL, Cochran JL, Price J, Butters MA et al (2011). fMRI correlates of white matter hyperintensities in late-life depression. Am J Psychiatry 168: 1075-1082.

Aizenstein HJ, Butters MA, Figurski JL, Stenger VA, Reynolds CF III, Carter CS (2005). Prefrontal and striatal activation during 
sequence learning in geriatric depression. Biol Psychiatry 58: 290-296.

Aizenstein HJ, Khalaf A, Walker SE, Andreescu C (2014). Magnetic resonance imaging predictors of treatment response in late-life depression. J Geriatr Psychiatry Neurol 27: 24-32.

Alexopoulos GS (2005). Depression in the elderly. Lancet 365: 1961-1970.

Alexopoulos GS, Glatt CE, Hoptman MJ, Kanellopoulos D, Murphy CF, Kelly RE Jr. et al (2010). BDNF val66met polymorphism, white matter abnormalities and remission of geriatric depression. J Affect Disord 125: 262-268.

Alexopoulos GS, Kiosses DN, Choi SJ, Murphy CF, Lim KO (2002). Frontal white matter microstructure and treatment response of late-life depression: a preliminary study. Am J Psychiatry 159: 1929-1932.

Alexopoulos GS, Meyers BS, Young RC, Campbell S, Silbersweig D, Charlson M (1997). 'Vascular depression' hypothesis. Arch Gen Psychiatry 54: 915-922.

Alexopoulos GS, Meyers BS, Young RC, Kakuma T, Feder M, Einhorn A et al (1996). Recovery in geriatric depression. Arch Gen Psychiatry 53: 305-312.

Alexopoulos GS, Murphy CF, Gunning-Dixon FM, Latoussakis V, Kanellopoulos D, Klimstra S et al (2008). Microstructural white matter abnormalities and remission of geriatric depression. Am J Psychiatry 165: 238-244.

Andreescu C, Butters MA, Begley A, Rajji T, Wu M, Meltzer CC et al (2008). Gray matter changes in late life depression-a structural MRI analysis. Neuropsychopharmacology 33: 2566-2572.

Beekman AT, Copeland JR, Prince MJ (1999). Review of community prevalence of depression in later life. $\mathrm{Br} J$ Psychiatry 174: 307-311.

Butters MA, Young JB, Lopez O, Aizenstein HJ, Mulsant BH, Reynolds CF 3rd et al (2008). Pathways linking late-life depression to persistent cognitive impairment and dementia. Dialog Clin Neurosci 10: 345-357.

Campbell S, Marriott M, Nahmias C, MacQueen GM (2004). Lower hippocampal volume in patients suffering from depression: a meta-analysis. Am J Psychiatry 161: 598-607.

Casten RJ, Rovner BW, Shmuely-Dulitzki Y, Pasternak RE, Pelchat R, Ranen N (1999). Predictors of recovery from major depression among geriatric psychiatry inpatients: the importance of caregivers' beliefs. Int Psychogeriatr/IPA 11: 149-157.

Chen PS, McQuoid DR, Payne ME, Steffens DC (2006). White matter and subcortical gray matter lesion volume changes and late-life depression outcome: a 4-year magnetic resonance imaging study. Int Psychogeriatr/IPA 18: 445-456.

Chen Y, Guo JJ, Li H, Wulsin L, Patel NC (2008). Risk of cerebrovascular events associated with antidepressant use in patients with depression: a population-based, nested casecontrol study. Ann Pharmacother 42: 177-184.

Chimowitz MI, Awad IA, Furlan AJ (1989). Periventricular lesions on MRI. Facts and theories. Stroke 20: 963-967.

Debette S, Seshadri S, Beiser A, Au R, Himali JJ, Palumbo C et al (2011). Midlife vascular risk factor exposure accelerates structural brain aging and cognitive decline. Neurology 77: 461-468.

Dew MA, Reynolds CF 3rd, Houck PR, Hall M, Buysse DJ, Frank E et al (1997). Temporal profiles of the course of depression during treatment. Predictors of pathways toward recovery in the elderly. Arch Gen Psychiatry 54: 1016-1024.

Dotson VM, Zonderman AB, Kraut MA, Resnick SM (2013). Temporal relationships between depressive symptoms and white matter hyperintensities in older men and women. Int $J$ Geriatr Psychiatry 28: 66-74.

Firbank MJ, Teodorczuk A, van der Flier WM, Gouw AA, Wallin A, Erkinjuntti $\mathrm{T}$ et al (2012). Relationship between progression of brain white matter changes and late-life depression: 3-year results from the LADIS study. Br J Psychiatry 201: 40-45.
Firbank MJ, Wiseman RM, Burton EJ, Saxby BK, O'Brien JT, Ford GA (2007). Brain atrophy and white matter hyperintensity change in older adults and relationship to blood pressure. Brain atrophy, WMH change and blood pressure. J Neurol 254: 713-721.

Frank E, Prien RF, Jarrett RB, Keller MB, Kupfer DJ, Lavori PW et al (1991). Conceptualization and rationale for consensus definitions of terms in major depressive disorder. Remission, recovery, relapse, and recurrence. Arch Gen Psychiatry 48: 851-855.

Garcia-Pena C, Wagner FA, Sanchez-Garcia S, Espinel-Bermudez C, Juarez-Cedillo T, Perez-Zepeda M et al (2013). Late-life depressive symptoms: prediction models of change. J Affect Disord 150: 886-894.

Grool AM, van der Graaf Y, Vincken KL, Witkamp TD, Mali WP, Geerlings MI (2013). Antidepressant use is related to larger white matter lesion volume in patients with symptomatic atherosclerotic disease: the SMART-MR study. J Neurol 260: 197-206.

Hajszan T, MacLusky NJ, Leranth C (2005). Short-term treatment with the antidepressant fluoxetine triggers pyramidal dendritic spine synapse formation in rat hippocampus. Eur J Neurosci 21: 1299-1303.

Halperin D, Reber G (2007). Influence of antidepressants on hemostasis. Dialogues Clin Neurosci 9: 47-59.

Hannestad J, Taylor WD, McQuoid DR, Payne ME, Krishnan KR, Steffens DC et al (2006). White matter lesion volumes and caudate volumes in late-life depression. Int J Geriatr Psychiatry 21: 1193-1198.

Heiden A, Kettenbach J, Fischer P, Schein B, Ba-Ssalamah A, Frey R et al (2005). White matter hyperintensities and chronicity of depression. J Psychiatric Res 39: 285-293.

Heo M, Murphy CF, Meyers BS (2007). Relationship between the Hamilton Depression Rating Scale and the Montgomery-Asberg Depression Rating Scale in depressed elderly: a meta-analysis. Am J Geriatr Psychiatry 15: 899-905.

Herrmann LL, Le Masurier M, Ebmeier KP (2008). White matter hyperintensities in late life depression: a systematic review. J Neurol Neurosurg Psychiatry 79: 619-624.

Jenkinson M, Beckmann CF, Behrens TE, Woolrich MW, Smith SM (2012). Fsl. NeuroImage 62: 782-790.

Katon W, Unutzer J, Russo J (2010). Major depression: the importance of clinical characteristics and treatment response to prognosis. Depr Anxiety 27: 19-26.

Kozel FA, Trivedi MH, Wisniewski SR, Miyahara S, Husain MM, Fava M et al (2008). Treatment outcomes for older depressed patients with earlier versus late onset of first depressive episode: a Sequenced Treatment Alternatives to Relieve Depression $\left(\mathrm{STAR}^{\star} \mathrm{D}\right)$ report. Am J Geriatr Psychiatry 16: 58-64.

Krishnan KR, Taylor WD, McQuoid DR, MacFall JR, Payne ME, Provenzale JM et al (2004). Clinical characteristics of magnetic resonance imaging-defined subcortical ischemic depression. Biol Psychiatry 55: 390-397.

Kupfer DJ (2005). Achieving adequate outcomes in geriatric depression: standardized criteria for remission. J Clin Psychopharmacol 25(Suppl 1): S24-S28.

Lebowitz BD, Pearson JL, Schneider LS, Reynolds CF 3rd, Alexopoulos GS, Bruce ML et al (1997). Diagnosis and treatment of depression in late life. Consensus statement update. JAMA 278: 1186-1190.

Lenze E, Cross D, McKeel D, Neuman RJ, Sheline YI (1999). White matter hyperintensities and gray matter lesions in physically healthy depressed subjects. Am J Psychiatry 156: 1602-1607.

MacQueen GM, Campbell S, McEwen BS, Macdonald K, Amano S, Joffe RT et al (2003). Course of illness, hippocampal function, and hippocampal volume in major depression. Proc Natl Acad Sci USA 100: 1387-1392.

Malberg JE, Eisch AJ, Nestler EJ, Duman RS (2000). Chronic antidepressant treatment increases neurogenesis in adult rat hippocampus. J Neurosci 20: 9104-9110.

Mulsant BH, Houck PR, Gildengers AG, Andreescu C, Dew MA, Pollock BG et al (2006). What is the optimal duration of a 
short-term antidepressant trial when treating geriatric depression? J Clin Psychopharmacol 26: 113-120.

Nelson JC, Delucchi KL, Schneider LS (2013). Moderators of outcome in late-life depression: a patient-level meta-analysis. Am J psychiatry 170: 651-659.

O'Brien J, Ames D, Chiu E, Schweitzer I, Desmond P, Tress B (1998). Severe deep white matter lesions and outcome in elderly patients with major depressive disorder: follow up study. BMJ 317: 982-984.

Reynolds CF 3rd, Dew MA, Frank E, Begley AE, Miller MD, Cornes C et al (1998). Effects of age at onset of first lifetime episode of recurrent major depression on treatment response and illness course in elderly patients. Am J Psychiatry 155: 795-799.

Reynolds CF III, Kupfer DJ (1999). Depression and aging: a look to the future. Psychiatr Serv 50: 1167-1172.

Rosano C, Becker J, Lopez O, Lopez-Garcia P, Carter CS, Newman A et al (2005). Morphometric analysis of gray matter volume in demented older adults: exploratory analysis of the cardiovascular health study brain MRI database. Neuroepidemiology 24: 221-229.

Saghafi R, Brown C, Butters MA, Cyranowski J, Dew MA, Frank E et al (2007). Predicting 6-week treatment response to escitalopram pharmacotherapy in late-life major depressive disorder. Int $J$ Geriatr Psychiatry 22: 1141-1146.

Schmidt R, Fazekas F, Kapeller P, Schmidt H, Hartung HP (1999). MRI white matter hyperintensities: three-year follow-up of the Austrian Stroke Prevention Study. Neurology 53: 132-139.

Sheline YI, Wang PW, Gado MH, Csernansky JG, Vannier MW (1996). Hippocampal atrophy in recurrent major depression. Proc Natl Acad Sci USA 93: 3908-3913.

Smith SM, Jenkinson M, Johansen-Berg H, Rueckert D, Nichols TE, Mackay CE et al (2006). Tract-based spatial statistics: voxelwise analysis of multi-subject diffusion data. NeuroImage 31: 1487-1505.

Smoller JW, Allison M, Cochrane BB, Curb JD, Perlis RH, Robinson JG et al (2009). Antidepressant use and risk of incident cardiovascular morbidity and mortality among postmenopausal women in the Women's Health Initiative study. Arch Intern Med 169: 2128-2139.

Steffens DC, Chung H, Krishnan KR, Longstreth WT Jr., Carlson M, Burke GL (2008). Antidepressant treatment and worsening white matter on serial cranial magnetic resonance imaging in the elderly: the Cardiovascular Health Study. Stroke 39: 857-862.

Streitburger DP, Moller HE, Tittgemeyer M, Hund-Georgiadis M, Schroeter ML, Mueller K (2012). Investigating structural brain changes of dehydration using voxel-based morphometry. PLoS One 7: e44195.

Taylor WD, Bae JN, MacFall JR, Payne ME, Provenzale JM, Steffens DC et al (2007). Widespread effects of hyperintense lesions on cerebral white matter structure. Am J Roentgenol 188: 1695-1704.

Taylor WD, Kudra K, Zhao Z, Steffens DC, MacFall JR (2014). Cingulum bundle white matter lesions influence antidepressant response in late-life depression: a pilot study. J Affect Disord 162: $8-11$.

Taylor WD, MacFall JR, Payne ME, McQuoid DR, Steffens DC, Provenzale JM et al (2005). Greater MRI lesion volumes in elderly depressed subjects than in control subjects. Psychiatry Res 139: 1-7.

Taylor WD, Steffens DC, MacFall JR, McQuoid DR, Payne ME, Provenzale JM et al (2003). White matter hyperintensity progression and late-life depression outcomes. Arch Gen Psychiatry 60: 1090-1096.

Taylor WD, Zhao Z, Ashley-Koch A, Payne ME, Steffens DC, Krishnan RR et al (2013). Fiber tract-specific white matter lesion severity findings in late-life depression and by AGTR1 A1166C genotype. Hum Brain Mapp 34: 295-303.

Teodorczuk A, O'Brien JT, Firbank MJ, Pantoni L, Poggesi A, Erkinjuntti $\mathrm{T}$ et al (2007). White matter changes and late-life depressive symptoms: longitudinal study. Br J Psychiatry 191: 212-217.

Teper E, O'Brien JT (2008). Vascular factors and depression. Int J Geriatr Psychiatry 23: 993-1000.

Thomas AJ, O'Brien JT, Davis S, Ballard C, Barber R, Kalaria RN et al (2002). Ischemic basis for deep white matter hyperintensities in major depression: a neuropathological study. Arch Gen Psychiatry 59: 785-792.

University of Pittsburgh, National Institutes of Health (2008). Duloxetine Treatment of Major Depression and Chronic Low Back Pain For Older Adults. National Institutes of Health: Bethesda, MD. University of Pittsburgh, National Institutes of Health (2009). Incomplete Response in Late Life Depression: Getting to Remission (IRL GREY). National Institutes of Health: Bethesda, MD.

University of Pittsburgh, National Institutes of Health (2010). ADAPT: Addressing Depression and Pain Together. National Institutes of Health: Bethesda, MDBethesda, MD.

van Dijk EJ, Prins ND, Vrooman HA, Hofman A, Koudstaal PJ, Breteler MM (2008). Progression of cerebral small vessel disease in relation to risk factors and cognitive consequences: Rotterdam Scan study. Stroke 39: 2712-2719.

Vermetten E, Vythilingam M, Southwick SM, Charney DS, Bremner JD (2003). Long-term treatment with paroxetine increases verbal declarative memory and hippocampal volume in posttraumatic stress disorder. Biol Psychiatry 54: 693-702.

Videbech P, Ravnkilde B (2004). Hippocampal volume and depression: a meta-analysis of MRI studies. Am J Psychiatry 161: 1957-1966.

Vythilingam M, Vermetten E, Anderson GM, Luckenbaugh D, Anderson ER, Snow J et al (2004). Hippocampal volume, memory, and cortisol status in major depressive disorder: effects of treatment. Biol Psychiatry 56: 101-112.

Wakana S, Jiang H, Nagae-Poetscher LM, van Zijl PC, Mori S (2004). Fiber tract-based atlas of human white matter anatomy. Radiology 230: 77-87.

Weeke P, Jensen A, Folke F, Gislason GH, Olesen JB, Andersson C et al (2012). Antidepressant use and risk of out-of-hospital cardiac arrest: a nationwide case-time-control study. Clin Pharmacol Ther 92: 72-79.

Whang W, Kubzansky LD, Kawachi I, Rexrode KM, Kroenke CH, Glynn RJ et al (2009). Depression and risk of sudden cardiac death and coronary heart disease in women: results from the Nurses' Health Study. J Am Coll Cardiol 53: 950-958.

Wu CS, Wang SC, Cheng YC, Gau SS (2011). Association of cerebrovascular events with antidepressant use: a casecrossover study. Am J Psychiatry 168: 511-521.

Wu M, Carmichael O, Lopez-Garcia P, Carter CS, Aizenstein HJ (2006a). Quantitative comparison of AIR, SPM, and the fully deformable model for atlas-based segmentation of functional and structural MR images. Hum Brain Mapp 27: 747-754.

Wu M, Rosano C, Butters M, Whyte E, Nable M, Crooks R et al (2006b). A fully automated method for quantifying and localizing white matter hyperintensities on MR images. Psychiatry Res 148: 133-142.

Zimmerman M, Posternak MA, Chelminski I (2004). Derivation of a definition of remission on the Montgomery-Asberg depression rating scale corresponding to the definition of remission on the Hamilton rating scale for depression. J Psychiatr Res 38: 577-582. 